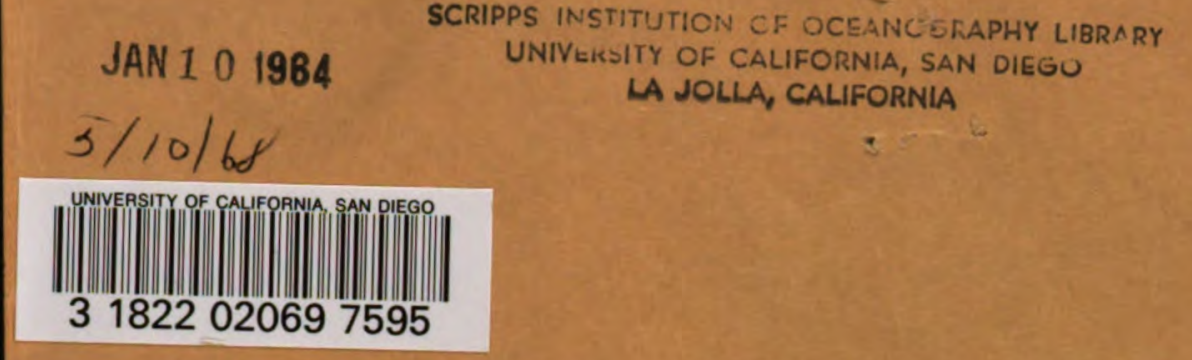

SHE UNIVERSITY LIBRARY UNIVERSITPRPF CALLFORNIA, SAN DIEGO

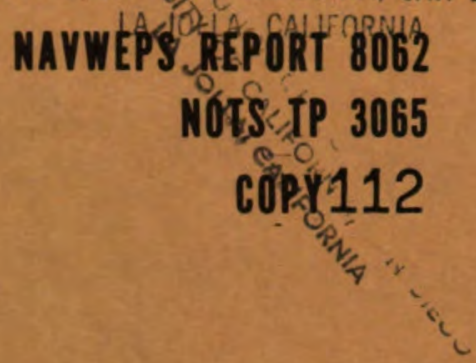

\title{
FLOW VISUALIZATION EXPERIMENTS WITH A DOLPHIN
}

\author{
by \\ Moe William Rosen \\ Underwater Ordnance Department
}

\begin{abstract}
The manner in which water flows about the body of a swimming dolphin is a subject concerning which little is known. In 1958, 2 years before the research described in this report, what appeared to be an immense transverse vortex was discovered by the author in the water spray over the back of a leaping dolphin. In addition, a peculiar system of large twin-armed transverse vortexes appeared in the spray wake behind its tail. Further original experiments that year with a fish led to the discovery by the author that a remarkable system of large discrete vortexes - the Fish Vortex Sys tem-exists in the water at the sides of a swimming fish. The resemblance of the dolphin's spray vortex to the fish vortexes in design and position was striking. These discoveries stimulated the further flow visualization research on dolphins reported here. The findings of this research indicate the presence of a vortex phenomenon under water about the body of a dolphin that resembles the Fish Vortex System.
\end{abstract}

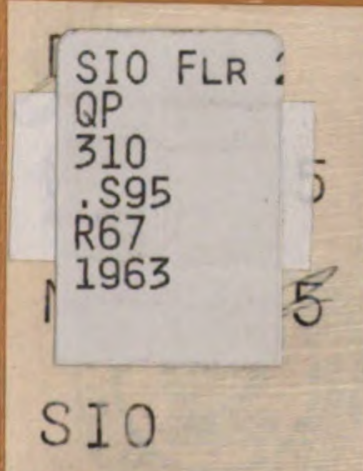

mainusisos

\section{U.S. NAVAL ORDNANCE TEST STATION}

\author{
China Lake, California
}

April 1963 